\title{
ALGUNAS REFLEXIONES A PROPÓSITO DE LA EJECUCIÓN DE LA HIPOTECA*
}

\author{
Some reflections on foreclosure
}

\author{
Jorge Alberto Beltrán Pacheco** \\ Universidad Continental
}

\section{Resumen}

En el presente trabajo, y a raíz de un adecuado análisis jurisprudencial, el autor muestra el panorama del proceso de ejecución de garantía hipotecaria, además realiza comentarios respecto a la competencia en este tipo de procesos.

Palabras clave: Hipoteca; excepción de incompetencia; argumentación; proceso único de ejecución.

\section{Abstract}

In the present work, as a result of a proper jurisprudential analysis, the author shows us the outlook of foreclosure process. Besides, the comments about the competence in these types of processes.

Key words: Mortgage; Exception of competence; argument; Civil Execution Act.

* Sirva el presente artículo para revisar algunos conceptos del Derecho Civil y del Derecho Procesal Civil, a propósito de los 30 años de vigencia de nuestra norma sustantiva civil, y solicitar a los magistrados del país una labor argumentativa creativa que permita una mejor aplicación de las normas jurídicas y el logro del desarrollo del país que tanto anhelamos.

** Abogado por la Pontificia Universidad Católica del Perú. Doctor en Derecho por la Pontificia Universidad Católica del Perú. Profesor en la Academia de la Magistratura, Pontificia Universidad Católica del Perú, Universidad Nacional Mayor de San Marcos y Universidad Continental de Huancayo. Socio del Estudio Beltrán. 


\section{RESOLUCIÓN CASATORIA N. 1361-2005-LA LIBERTAD:}

Con fecha 11 de agosto de 2005 la SALA CIVIL PERMANENTE DE LA CORTE SUPREMA DE JUSTICIA emite la siguiente resolución casatoria:

«VISTOS Y ATENDIENDO: PRIMERO: El recurso de casación interpuesto cumple con las exigencias de forma establecidas para su admisibilidad, no siendo necesario que el recurrente acredite el cumplimiento del requisito de fondo previsto en el artículo 388 inciso 1 del CPC, al haber obtenido pronunciamiento favorable en primera instancia. SEGUNDO: Que como causal del recurso propuesto invoca aquella contenida en el inciso dos del artículo 386 del CPC, esto es inaplicación de una norma de derecho material. TERCERO: Que como fundamento de la causal, señala que se ha inaplicado el artículo 34 del CÓDIGO CIVIL, ya que la Sala Superior no ha tenido presente que existe un acuerdo expreso entre la ejecutante y ejecutados, en relación al sometimiento expreso a los juzgados y tribunales de Lima al tratarse el pagare de la obligación principal, mientras que la hipoteca otorgada no es otra cosa que la garantía que respalda el cumplimiento de la obligación principal; por lo tanto al ser el pagare la obligación principal y la hipoteca únicamente la garantía otorgada para el cumplimiento de pago de la primera, la Sala deberá entender que en un supuesto de que se de un incumplimiento, existe un conflicto en cuanto a la renuncia a una jurisdicción determinada, siendo que la hipoteca constituye un derecho real de garantía, cuyo único sustento se encuentra en brindar seguridad de cobro al acreedor, se deberá entender que su carácter es únicamente accesorio, mas no podría en ningún caso constituir una obligación, debido a que siempre depende de la preexistencia de una obligación de naturaleza civil, que en el presente caso se encuentra constituida en el pagare. CUARTO: analizando dicha causal, se tiene que la misma no resulta atendible debido a que la aplicación de dicha norma en nada cambiaría el sentido de la decisión, toda vez que revisados los autos, se tiene que el título es la escritura pública donde aparece la garantía y el saldo deudor, y el pagare sólo es una prueba. POR LAS RAZONES EXPUESTAS y haciendo uso de la Facultad prevista en el artículo 392 del CPC declararon IMPROCEDENTE el recurso de casación interpuesto por INVERJUNIN S.A.C en los seguidos por el BANCO DEL NUEVO MUNDO sobre ejecución de garantía y CONDENARON al recurrente al pago de la multa de 3 URP así como las costas y costos originados en la tramitación del recurso; DISPUSIERON la publicación de la presente resolución en el diario oficial EL PERUANO bajo responsabilidad.» 


\section{INTRODUCCIÓN}

La resolución casatoria objeto del presente estudio es el resultado de un proceso de ejecución de garantía real hipotecaria iniciado por el Banco del Nuevo Mundo contra Inversiones Peruanas S. A. y Sociedad Conservera del Norte S. A., siendo incorporado al proceso Inverjunin S.A.C. como propietario del bien objeto de hipoteca. En este proceso el ejecutado Sociedad Conservera del Norte S.A. formuló una excepción de incompetencia contra el ejecutante aduciendo que en el pagaré (título valor garantizado con la hipoteca, entre una serie de deudas garantizadas) se había pactado que los jueces de Lima tendrían la competencia jurisdiccional ante cualquier conflicto suscitado respecto del título valor. No obstante, el ejecutante sostiene que en la Escritura Pública de la Hipoteca se señalaba que la competencia correspondía a los jueces de Trujillo. En este contexto es que efectuaremos nuestro comentario, proponiendo en primer lugar unas ideas sobre la naturaleza de la ejecución de garantías reales, para luego comentar la excepción de incompetencia planteada y concluir con un comentario a la resolución casatoria.

\section{NATURALEZA DE LA PRETENSIÓN EN EL PROCESO DE EJECUCIÓN DE GARANTÍA HIPOTECARIA}

En lo que concierne al aspecto sustantivo debemos indicar que la hipoteca es una garantía real (derecho real de garantía) que respalda la ejecución (cumplimiento) de una deuda civil por lo que no podemos confundir la ejecución de la hipoteca con una acción real como de modo errado alguna jurisprudencia lo ha intentado esbozar:

«El proceso de ejecución de garantías es una acción real que corresponde al titular de un derecho real de garantía, para ser efectiva la venta de la cosa por incumplimiento de la obligación garantizada, lo que se despacha en virtud del título ejecutivo constituido por el documento perfecto que contiene la garantía, copulativamente con el estado de cuenta del saldo deudor». (Casación N. ${ }^{\circ}$ 1693-98-LA LIBERTAD del 22 de enero de 1999).

Mediante la hipoteca buscamos realizar la prestación a través de un cumplimiento «sustituto» puesto que la prestación de dar suma de dinero que originariamente debía ser cumplida se materializa mediante el precio resultante de la ejecución del bien objeto de garantía.

Resulta importante indicar que en el presente caso (de ejecución de garantías) lo que buscamos es satisfacer el interés del acreedor que se encuentra impago, así tenemos que en este proceso el ejecutante tiene que presentar 
el «estado de cuenta del saldo deudor»' para efectos de determinar el contenido del interés insatisfecho².

Algunas casaciones ${ }^{3}$ al respecto:

«Para establecer la obligación cierta, expresa y exigible (...) se debe presentar el estado de cuenta del saldo deudor que se encuentra a cargo del ejecutado». (Casación № 2701-97-AREQUIPA del 13 de diciembre de 1999).

«Para la procedencia de la acción de ejecución de garantías sólo se requiere la existencia de una deuda exigible garantizada por el documento que contiene la garantía (...) siendo irrelevante si el pagaré que representada la deuda que se pretende cobrar tenía o no mérito ejecutivo, pues de su inejecutabilidad en la vía ejecutiva no se puede concluir que la deuda representada en él sea inexigible». (Casación $N^{\circ}$ 212-96-PIURA del 21 de abril de 1998).

«El estado de cuenta de saldo deudor constituye una operación en la que se establece la situación en que se encuentra el deudor respecto de las obligaciones que ha contraído, verificándose desde el punto de vista del acreedor si la deuda está impaga o cancelada (...) que este requisito (el saldo deudor) no está sujeto a una forma preestablecida en la ley procesal, lo que implica que puede cumplirse con él sin que necesariamente el documento que lo contiene se denomine estado de cuenta del saldo deudon). (Casación N 1545-98-Huánuco del 2 de enero de 1999).

Tal como lo podemos apreciar el proceso único de ejecución (de ejecución de garantías) no puede ser confundido con el proceso de ejecución de dar

1 Conforme al artículo 720 del Código Procesal Civil, modificado por el Decreto Legislativo 1069 del 27 de Junio de 2008, se tienen como requisitos de procedencia de la ejecución de garantías lo siguiente: «1. Procede la ejecución de garantías reales, siempre que su constitución cumpla con las formalidades que la ley prescribe y la obligación garantizada se encuentre contenida en el mismo documento o en cualquier otro tí́tulo ejecutivo; 2 . El ejecutante anexará a su demanda el documento que contiene la garantía y el estado de cuenta del saldo deudor; 3 . Si el bien fuere inmueble, debe presentarse documento que contenga tasación comercial actualizada realizada por dos ingenieros y/o arquitectos colegiados, según corresponda con sus firmas legalizadas. (...); 4. No será necesaria la presentación de nueva tasación si las partes han convenido el valor actualizado de la misma; 5. Tratándose de bien registrado se anexará el respectivo certificado de gravamen. (...)» (El énfasis es propio).

2 La ejecución de la garantía real hipotecaria no centra su atención en el bien inmueble objeto del derecho real de hipoteca como centro del interés del acreedor, es decir, no es el caso que el acreedor tenga «interés en adquirir el inmueble como objeto de su satisfacción», sino lo que se persigue es «realizar la hipoteca» constituida sobre el bien para mediante el precio obtenido en el remate hacer efectivo el pago de la deuda dineraria a favor del acreedor.

3 Las resoluciones casatorias fueron extraídas de ARIANO, Eugenia. «Título, partes y terceros en la denominada ejecución de garantías». En Cuadernos Jurisprudenciales n. ${ }^{\circ}$ 7. Lima: Gaceta Jurídica, enero 2002. 
suma de dinero puesto que en el segundo se ejecuta un título ejecutivo que contiene una deuda (dineraria), como es el caso de un título valor (letra de cambio, cheque o pagaré) mientras que en el primero se ejecuta una garantía real (como la hipoteca) para que mediante el precio del remate del bien se cumpla la prestación de dar suma de dinero impaga. En tal sentido, no es correcto alegar aspectos del contenido del pagaré ${ }^{4}$ en el proceso de ejecución de garantía hipotecaria como lo hace el ejecutado quien estableció que en el pagaré se había señalado el sometimiento de las partes a Lima y no a Trujillo (que es la competencia prevista en la escritura pública de constitución de hipoteca). Algunas jurisprudencias establecen al respecto:

«En el proceso de ejecución de garantías el título de ejecución está constituido por el documento que contiene la garantía copulativamente con el estado de cuenta de saldo deudor (...) y no por los títulos valores que se puedan anexar para acreditar el desembolso del dinero». (Casación N. ${ }^{\circ} 1169-1998-P I U R A$ del 21 de diciembre de 1998).

«Para la procedencia de la acción de ejecución de garantías sólo se requiere la existencia de una deuda exigible garantizada por el documento que contiene la garantía (...) siendo irrelevante si el pagaré que representada la deuda que se pretende cobrar tenía o no mérito ejecutivo, pues de su inejecutabilidad en la vía ejecutiva no se puede concluir que la deuda representada en él sea inexigible». (Casación N. ${ }^{\circ}$ 212-96-PIURA del 21 de abril de 1998).

"La exigencia contenida en el artículo 720 del Código Procesal Civil (en adelante, el CPC) no incluye la de recaudar pagaré o algún otro documento que acredite el saldo deudor que el ejecutado no haya pagado, bastando con la presentación del documento que contiene la garantía y el estado de cuenta del saldo deudor». (Casación N. ${ }^{\circ}$ 563-1996-AREQUIPA del 2 de mayo de 1998).

No obstante lo explicado, debemos señalar, tal como lo dice Martell5, que:

4 No obstante veremos que en numerosos casos se suele citar a la deuda contenida en el pagaré para justificar la existencia de un interés crediticio insatisfecho que justifique la ejecución de la hipoteca. Es importante señalar que la hipoteca se constituyó, en el presente caso, para garantizar toda deuda que el cliente bancario tenga con el banco, por lo que «la hipoteca» garantizó a un contrato de mutuo que suscribió Sociedad Conservera del Norte con el Banco del Nuevo Mundo en el que, además, se emitió un pagaré. De acuerdo al Código Procesal Civil la acreditación de la deuda impaga se realiza con el documento en el que figura «el saldo deudon».

5 MARTEL, Rolando. «Proceso de ejecución de garantías: revisando la praxis judicial». En Cuadernos Jurisprudenciales n. ${ }^{\circ}$ 7. Lima: Gaceta Jurídica, enero 2002. A propósito de lo indicado por el referido autor debemos señalar que nos preocupa la práctica judicial citada puesto que al ejecutarse un título valor (que tiene como relación jurídica sustantiva de base a una deuda civil «X») Y EN PARALELO solicitarse la ejecución de una hipoteca que garantiza 
Tratándose de obligaciones contenidas en títulos valores o de otra índole que derivan después en títulos ejecutivos y que se encuentran respaldadas con garantía real, es factible que el acreedor ejecutante pueda instaurar un proceso ejecutivo recaudando al efecto el título ejecutivo, o un proceso de ejecución de garantía real anexando el respectivo título de ejecución y necesariamente, en este último proceso, el documento que acredite la exigibilidad de la obligación, documento que puede ser un título valor.

Es decir, que podría iniciar primero el proceso ejecutivo y luego el de ejecución de garantías, o viceversa, o simultáneamente.

Así viene ocurriendo en la praxis judicial y se ha encontrado por lo menos dos criterios jurisdiccionales en todas las instancias que resuelven de manera diferente y contraria estos casos. Un criterio admite la posibilidad de instaurar ambas demandas y el otro la niega.

A manera de ilustración de tales criterios nos remitimos a dos resoluciones casatorias publicadas recientemente en el diario oficial que dan cuenta de los fundamentos que sustentan cada criterio.

Principalmente se sostiene en el primer caso que ambos procesos, ejecutivo y de ejecución de garantía, se rigen por normas especiales, no son excluyentes uno del otro, tal como lo establece el artículo 1117 del Código Civil, razón por la cual es posible jurídicamente iniciar un proceso de ejecución de garantías sobre la base del mismo pagaré que sustenta el proceso ejecutivo ya iniciado.

El criterio contrario sostiene básicamente que al ser la misma obligación la que se reclama en ambos procesos, existe un mismo petitorio e interés para obrar, y es, por lo tanto, en virtud del artículo 438 inciso 3 del Código Procesal Civil, imposible jurídicamente iniciar un proceso con el mismo petitorio.

Por tanto, la ejecución de garantías es una pretensión de carácter real y no debe ser confundida con la pretensión de ejecución de dar suma de dinero que puede recaer sobre el pagaré objeto de cobro. Este es un primer aspecto que nos conduce a afirmar que las normas jurídicas privadas previstas por la potestad normativa (de la voluntad de los sujetos) en el contrato de hipoteca (que constituye el derecho real de hipoteca) tienen autonomía respecto de las previstas en el pagaré y, por tanto, las reglas sobre competencia resultan independientes y vinculantes.

la misma deuda civil «X» entonces se estaría cobrando dos veces la misma deuda. En este caso, si el proceso de ejecución de dar suma de dinero se inicia después que el proceso de ejecución de garantías reales debería presentarse una excepción al momento de contradecir que sustente la existencia del doble cobro. 
En el presente proceso aduciendo la accesoriedad de la hipoteca se formuló una excepción de incompetencia que evaluamos a continuación y que resulta paso necesario para comentar la casación objeto de estudio.

\title{
III. EXCEPCIÓN DE INCOMPETENCIA Y SANEAMIENTO DEL PROCESO
}

Tal como lo habíamos señalado, la parte demandada Sociedad Conservera del Norte S.A. deduce la excepción de incompetencia mediante los siguientes fundamentos:

«EXCEPCIONES: en el mismo escrito de contradicción el demandado SOCIEDAD CONSERVERA DEL NORTE S.A deduce la EXCEPCIÓN DE INCOMPETENCIA por los siguientes fundamentos: conforme se desprende de manera expresa del pagaré N ${ }^{\circ} 090330$ de fecha 04 de noviembre de 1999 se estableció de manera indubitable que las partes intervinientes renunciaban al fuero de su propio domicilio aceptando someterse a los jueces y tribunales del Distrito Judicial de Lima Metropolitana y no al de Trujillo como lo sostiene el BANCO DEL NUEVO MUNDO; por tanto es competente el juzgado especializado en lo civil de Lima y no el juzgado especializado en lo civil de Trujillo; presenta como medio probatorio el pagaré $\mathrm{N} .^{\circ} 090330$ de fecha 04 de noviembre de 1999».

Ante la cual el Banco del Nuevo Mundo (ejecutante) absuelve del siguiente modo:

\begin{abstract}
«ABSOLUCIÓN DE LA EXCEPCIÓN: Con fecha 14 de enero de 2002 BANCO NUEVO MUNDO EN LIQUIDACIÓN se apersona al proceso y absuelve la contradicción con los siguientes fundamentos: RESPECTO DE LA EXCEPCIÓN DE INCOMPETENCIA se indica que la escritura pública de otorgamiento de crédito y constitución de hipoteca de fecha 12 de octubre de 1999 constituye el título de ejecución en el proceso y no el pagaré $\mathrm{N}^{\circ} 090330$ por lo que siendo la primera un instrumento público por mandato de lo dispuesto por el artículo 235 del CPC goza de fe notarial y cumple con los requisitos de los artículos 1097, 1098 y 1099 del C. Civil no adoleciendo de defecto formal que lo invalidez siendo válido el emplazamiento de la ejecutada; en este sentido el PLENO JURISDICCIONAL CIVIL de setiembre de 1999 estableció que «no es exigible la presentación del título valor o el documento que acredite la obligación, basta con el documento que contiene la garantía y el estado de cuenta del saldo deudons'; del mismo modo
\end{abstract}

6 Al respecto debemos señalar que en la judicatura peruana también se ha cuestionado la «inseguridad» que genera la presentación de un «documento simple» que indique cuál es el 
la jurisprudencia es abundante respecto de lo expuesto indicando que «en el proceso de ejecución de garantía, el título está constituido por aquel documento que contiene la obligación con garantía real previamente constituida, a diferencia del proceso ejecutivo en que la acción procede en virtud de cualquiera de los títulos a los que la Ley reconoce como ejecutivos» (expediente N. ${ }^{\circ}$ 0578-7-97); por otro lado se indica en el expediente N. ${ }^{\circ} 189-97$ que «la garantía real materia de ejecución está contenida en la escritura pública de constitución de hipoteca que corre... Los requisitos para la admisión a trámite de la ejecución de garantía se encuentran establecidos en el artículo 720 del Código Procesal Civil, no siendo necesaria la presentación del pagaré para acreditar la obligación impaga, pues este título no es materia de la ejecución y por lo tanto no se encuentra en discusión si el pagare tiene o no mérito ejecutivo».

\subsection{Concepto y tipología de excepciones}

La excepción es un medio de defensa de forma (aunque en la actualidad de la dogmática procesal se considera que también existe una vinculación con el fondo del proceso ${ }^{7}$, al discutir la validez de la relación jurídica procesal que refiere a aspectos sustantivos: relación jurídica sustantiva, como es el caso de la "falta de legitimidad para obrar del demandante» en la que tendría que evaluarse si el demandante tiene derecho para actuar lo que nos conduce a un estudio del derecho subjetivo) por la que se cuestiona el cumplimiento de los presupuestos procesales y de las condiciones de la acción y por tanto la validez de la relación jurídica procesal.

La excepción puede ser perentoria o dilatoria en la medida que concluya el proceso o lo retarde (en tanto puede subsanarse). Así el artículo 446 del Código Procesal Civil establece cuáles son los distintos tipos de excepciones existentes:

«Artículo 446.- Excepciones proponibles.- El demandado sólo puede proponer las siguientes excepciones:

1. Incompetencia.

2. Incapacidad del demandante o de su representante.

saldo deudor lo que debería estar complementado con información fehaciente de la existencia de dicho monto. Del mismo modo se indica que no obstante no se discuta la existencia de una deuda preexistente debería presentarse un documento en el que figure tal deuda dado que la hipoteca (que busca ejecutarse) la garantiza.

7 Por ejemplo, ¿cómo evaluar la falta de legitimidad para obrar del demandante sin analizar aspectos de la relación jurídica sustantiva en la que el demandante haya cedido su derecho (lo que le impide demandar) o haya sido sujeto beneficiario de una cesión la que se considera nula? 
3. Representación defectuosa o insuficiente del demandante o del demandado.

4. Oscuridad o ambigüedad en el modo de proponer la demanda.

5. Falta de agotamiento de la vía administrativa.

6. Falta de legitimidad para obrar del demandante o del demandado.

7. Litispendencia.

8. Cosa Juzgada.

9. Desistimiento de la pretensión.

10. Conclusión del proceso por conciliación o transacción.

11. Caducidad.

12. Prescripción extintiva.

13. Convenio Arbitral».

\subsection{Excepción de incompetencia}

De acuerdo al artículo antes citado, el sujeto, quien postula una excepción, puede cuestionar la competencia del juez que conoce el proceso por lo que propondrá la incompetencia del magistrado ante quien se presenta la pretensión de ejecución.

Así la incompetencia alude a un presupuesto procesal (son tres: la capacidad de las partes; la competencia del juez y los requisitos de la demanda) siendo éste la competencia que refiere a «la facultad que tiene un juez de conocer determinado conflicto sea por estar en los límites de su territorio, por tener la especialidad correspondiente (familia, ejemplo), por corresponderle según cuantía, por ser el juez de turno o grado».

La competencia puede ser absoluta (cuando no se puede modificar) o relativa (cuando se produce la prórroga tácita de la competencia para el demandante por el hecho de interponer la demanda y para el demandado por comparecer al proceso sin hacer reserva o dejar transcurrir el plazo sin cuestionar la competencia).

De acuerdo con el artículo 6 del CPC: «La competencia sólo puede ser establecida por la Ley. La competencia civil no puede renunciarse ni modificarse, salvo en aquellos casos expresamente previstos en la ley o en los convenidos internacionales respectivos». Asimismo, de acuerdo al artículo 7 del CPC, «[n]ingún juez civil puede delegar en otro la competencia que 
la ley le atribuye. Sin embargo, puede comisionar a otro la realización de actuaciones judiciales fuera de su ámbito de competencia territorial».

\subsubsection{Determinación de la competencia}

Si estamos ante la competencia por materia, de acuerdo al artículo 9 del CPC, ésta se determina por la naturaleza de la pretensión y por las disposiciones legales que la regulan.

Si nos referimos a la competencia por cuantía, ésta se determina de acuerdo al valor económico del petitorio, según las reglas del artículo 10 del CPC, es decir: según lo expresado en la demanda. Si aparece en la demanda o en los anexos que la cuantía es distinta a la indicada por el demandante, entonces el juez efectuará la corrección.

En el caso de personas naturales debe ser competente el juez del lugar de su domicilio, salvo disposición legal en contrario (Art. 14 del CPC). Si tiene diversos domicilios, puede ser demandado en cualquiera de ellos.

En el caso de personas jurídicas es competente el juez del domicilio en donde tiene su sede principal, salvo disposición legal en contrario (Art. 17 del CPC). $\mathrm{Si}$ es que la persona jurídica cuenta con sucursales, agencias, establecimientos 0 representantes debidamente autorizados en otros lugares, puede ser demandada a elección del demandante ante el juez del domicilio de la sede principal o el de cualquiera de dichos domicilios en donde ocurrió el hecho que motiva la demanda o donde sería ejecutable la pretensión reclamada.

Es posible que la competencia sea facultativa cuando queda a elección del demandante en casos como pretensiones sobre derechos reales (se demanda donde está el bien), el lugar donde debe cumplirse la obligación, el lugar donde ocurrió el daño (en caso de indemnizaciones), entre otros, según el artículo 24 del CPC.

De acuerdo al artículo 25 del CPC, «las partes pueden convenir por escrito someterse a la competencia territorial de un juez distinto al que corresponde, salvo que la ley la declare improrrogable» ${ }^{8}$. En el presente caso las partes se sometieron a la competencia del juez de Trujillo por lo que es plenamente válido que se demande en dicha ciudad.

Según el artículo 34 del CPC «los procesos de ejecución se someten a las reglas generales sobre competencia, salvo disposición distinta de este Có-

8 Este artículo refiere a la capacidad normativa de los sujetos quienes en ejercicio de su autonomía privada y en específico de la libertad de autorregulación o configuración interna establecen «normas jurídicas privadas» que regulen el desarrollo de sus actos. 
digo». Por tanto, es posible que las partes se sometan a una competencia diferente a la señalada en el contrato principal.

\subsubsection{Cuestionamiento de competencia y excepciones}

De acuerdo con el artículo 35 del CPC, la incompetencia por razón de materia, cuantía y territorio (cuando es improrrogable) se declara de oficio en cualquier estado y grado del proceso, sin perjuicio que pueda ser invocada como excepción. En este caso cuando el juez declara su incompetencia también declara la nulidad de lo actuado y la conclusión del proceso.

En este caso deberá remitirse el proceso al órgano señalado en el artículo 36 del CPC, por ejemplo a la Sala Civil de la Corte Superior o Suprema que corresponda (en el caso de la incompetencia territorial).

En el caso de la incompetencia por territorio se puede cuestionar la misma mediante inhibitoria o excepción conforme al artículo 37 del CPC. La inhibitoria se interpone por el demandado ante el juez que considere competente, dentro de cinco días de emplazado, ofreciendo los medios probatorios correspondientes. De ser el caso que el juez se declare competente, entonces oficiará a aquel que conoce el proceso solicitándole que se inhiba y le remita el expediente (Art. 39 del CPC). El juez que recibe el oficio comunicará al demandante la interposición de la inhibitoria y dispondrá la suspensión del proceso. El demandante puede contradecir la inhibitoria y ofrecer medios probatorios dentro del tercer día de notificado. Si el juez se inhibe entonces remitirá todo lo actuado al juez que solicita mientras que si no considera ser incompetente remitirá lo actuado al superior para que dirima la competencia (Art. 40 del CPC).

El proceso se suspende, pero cualquiera de los dos jueces puede dictar medidas cautelares si a su criterio la omisión pudiera provocar perivicio irreparable para las partes o los terceros (Art. 42 del CPC).

La excepción, mientras tanto, es presentada al mismo juez quien resolverá en el proceso si procede o no su incompetencia. Ello se resolverá en la audiencia de saneamiento en un proceso de conocimiento. Mientras que en el caso de los procesos de ejecución de garantías, se resolverá en la sentencia o auto que resuelve la contradicción.

Existe un problema que consideramos opinar de modo breve: la excepción en el proceso de ejecución de garantías.

Al inicio nuestra opinión era la imposibilidad de formular una excepción en

el proceso de ejecución de garantías, pero luego de un estudio minucioso 
opinamos que sí es posible porque no podemos limitar el derecho a la defensa y a la tutela jurisdiccional al impedir la interposición de excepciones.

El problema inicial que enfrentamos fue que el artículo 722 del CPC, sobre contradicción (en el proceso de ejecución de garantías), NO SEÑALA que es posible sustentar la contradicción mediante excepciones puesto que sólo establece que se puede «alegar la nulidad formal del título, la inexigibilidad de la obligación o que la misma ya ha sido pagada o ha quedado extinguida de otro modo, o que se encuentra prescrita». Indica, además, que «la contradicción que se sustente en otras causales será rechazada liminarmente por el juez, siendo esta decisión apelable sin efecto suspensivo».

Este artículo difiere con el artículo 700 del CPC (sobre ejecución de dar suma de dinero) que establece que la contradicción se puede sustentar en excepciones y defensas previas. Por tanto, para nuestro entender no era posible presentar excepciones en el proceso de ejecución de garantías reales, dado que el CPC la había excluido por alguna razón. Pero no fue así dado que el CPC no la excluyó por imposibilidad sino por defecto de regulación. Así tenemos que la Corte Suprema de Justicia ha considerado que sí es posible interponer excepciones en el proceso de ejecución de garantías y, por tanto, este proceso no tendría problemas al respecto. No obstante, este tema no es pacífico.

Sobre la excepción planteada, debemos indicar que no estamos de acuerdo con ella, puesto que las partes acordaron que la competencia en la ejecución de garantías reales sería Trujillo y no Lima (como en el pagaré) y, si bien es cierto la hipoteca es accesoria a la deuda civil o mercantil (pagaré), no es cierto que en asuntos de competencia deba someterse a las reglas de la deuda principal ya que por especialidad se estableció en las reglas jurídicas privadas de la hipoteca que sería competente el juez de Trujillo. Más aún, en caso de ejecución se puede demandar en el lugar donde se ubica el bien inmueble.

\section{COMENTARIOS A LAS RESOLUCIONES PREVIAS A LA RESOLUCIÓN CASATORIA EN EL PROCESO DE EJECUCIÓN DE GARANTÍAS OBJETO DE ESTUDIO}

Para mejor entender la resolución casatoria, materia de análisis, consideramos pertinente efectuar algunos cortos comentarios a las resoluciones emitidas por el juez de primera instancia y la Sala Superior (ante el recurso de apelación). De este modo podemos conocer mejor cómo fue el razonamiento jurídico aplicado en el presente proceso. 


\subsection{Resolución $\mathbf{N} .^{\circ} 12$ (auto que resuelve la contradicción)}

A fojas 198 a 199 obra la Resolución No 12 que resuelve declarar infundadas la excepción de incompetencia y la contradicción por inexigibilidad de la obligación ordenando se lleve a cabo el remate del bien inmueble objeto de garantía hipotecaria, por los siguientes fundamentos:

«Tercero.- Que, conforme se verifica de la cláusula décimo segunda de la Escritura Pública de constitución de hipoteca corriente en fojas 27 a 33 las partes contratantes se comprometen a someterse expresamente a la competencia de los jueces y tribunales de la ciudad de Trujillo para todos los efectos de dicho contrato de garantía; lo que quiere decir, que libre y convencionalmente han aceptado la competencia territorial de este juzgado en el supuesto caso de la ejecución de tal garantía conforme lo estipula el artículo 25 del CPC, por lo que, la excepción deducida no puede ser amparada. Cuarto.- Que, así mismo, la contradicción formulada tampoco puede ser amparada por cuanto, la ejecutada no ha cumplido con acreditar la supuesta negociación realizada con la entidad ejecutante conforme lo exige el artículo 196 del citado Código adjetivo, a fin de poder verificar si efectivamente existía nuevos acuerdos adoptados respecto al plazo de vencimiento, lugar, modo o condición de pago de la deuda demandada para que ésta pueda resultar inexigible, no teniendo nada que ver con dicha causal el hecho de que la ejecutante haya presentado una nueva valorización del inmueble hipotecado inferior a la acordada convencionalmente». (El énfasis es propio).

Estamos de acuerdo con el autoobjeto de análisis en lo que respecta a la excepción de incompetencia, pero no plenamente sobre lo que refiere a la contradicción puesto que debió evaluar mejor el contenido de la inexigibilidad ${ }^{9}$ de la deuda además que no evalúa lo que la parte demandada alega: la devolución de los montos por SUNAT.

Debemos señalar que inexigibilidad refiere a «que la deuda no es exigible» o «cobrable». No es el caso de «la existencia de un acuerdo o pacto sobre lo adeudado», que refiere más a un supuesto de «inexistencia de incumplimiento» que es presupuesto para el cobro de la deuda, aunque para un sector de abogados (desde una lectura literal) pudiera ser que «inexigible»

9 El artículo 722 del Código Procesal Civil, modificado por el artículo único del Decreto Legislativo 1069, publicado el 27 de Junio de 2008, refiere que «[e]l ejecutado, en el mismo plazo que tiene para pagar, puede contradecir con arreglo a las disposiciones generales». Por su parte el artículo 690-D del mismo dispositivo procesal, introducido por el artículo único del Decreto Legislativo antes citado, señala: que «["]]a contradicción sólo podrá fundarse según la naturaleza del título en: 1. Inexigibilidad o iliquidez de la obligación contenida en el título; 2. Nulidad formal o falsedad del título; o cuando siendo éste un título valor emitido en forma incompleta, hubiere sido completado en forma contraria a los acuerdos adoptados, debiendo en este caso observarse la ley de la materia; 3. La extinción de la obligación exigida (...)» 
refiera a que el plazo aún no se ha cumplido o vencido por lo que la deuda aún no está impaga. Respetamos criterios.

\subsection{Resolución $\mathbf{N} .^{\circ} 18$}

A fojas 236 la segunda sala civil de la Corte Superior de Justicia de La Libertad se resuelve la apelación interpuesta por Sociedad Conservera del Norte S.A. declarando confirmar el auto de fojas 198 a 199 de fecha 18 de junio del 2003 que declara infundada la excepción de incompetencia y la contradicción por inexigibilidad de la obligación deducidas por el gerente General de la coejecutada Sociedad Conservera del Norte S. A. y en consecuencia ordena se lleve a cabo el remate. Los fundamentos de esta resolución son:

«TERCERO: en la cláusula décima segunda del referido documento (que contiene la garantía) corriente a fojas 27 las partes convienen en que para los efectos del contrato se someten expresamente a la competencia de los jueces y tribunales de Trujillo; CUARTO: Que, las partes pueden convenir por escrito, como aparece del instrumento glosado, someterse a la competencia territorial de un Juez distinto al que le corresponde en aplicación del artículo 25 del Código Procesal Civil, por la que la excepción promovida por el ejecutado debiendo notoriamente infundada; QUINTO: Que, el ejecutado deduce contradicción sustentándola en la inexigibilidad de la obligación argumentando que se niega a cancelarlo la que condiciona a la devolución del dinero que debe hacerle la SUNAT; SEXTO: Que, los argumentos que expone el ejecutado no son los idóneos para sustentar una contradicción basada en la inexigibilidad de la obligación puesta debe circunscribirse a sostener que la obligación no es pura ni simple, o que el plazo no ha vencido o que se encuentra sujeto a condición.»

Nuevamente estamos de acuerdo con lo resuelto, puesto que la excepción no debe ser amparada. Por otro lado, en lo que refiere a la contradicción, debemos señalar que el argumento del derecho existente frente a SUNAT (la deuda que SUNAT tiene con Sociedad Conservera del Norte S.A.) no es oponible porque no refiere a los supuestos del artículo 722 del CPC (concordado con el artículo 690-D del CPC).

Sobre la inexigibilidad refiere a supuestos tales como «sostener que la obligación no es pura ni simple, o que el plazo no ha vencido o que se encuentra sujeto a condición». Que alude a situaciones en las que la deuda no es posible de ser requerida a cobro que no es propiamente el caso del expediente puesto que la argumentación de la ejecutada es que tiene voluntad de pago pero al parecer no tiene dinero para ello, lo que es un 
problema de insolvencia o incapacidad económica de pago. No estamos considerando que la sentencia esté incorrecta en este aspecto, puesto que es la parte demandada quien sostiene que existe una inexigibilidad de la obligación, lo que no resulta conforme a ley.

Es importante «sostener que la obligación no es pura ni simple, es lo mismo que decir que existe una modalidad de la obligación: plazo, condición, modo o cargo» por lo que es reiterativa la resolución cuando dice: «que el plazo no ha vencido o que se encuentra sujeto a condición».

\section{APRECIACIONES FINALES A LA RESOLUCIÓN CASATORIA OBJETO DE ESTUDIO}

Finalmente, podemos indicar que nos encontramos de acuerdo con la resolución, pero no con los fundamentos porque (tal como lo hemos señalado) las partes pueden pactar válidamente (Art. 25 del CPC) que la competencia territorial sea distinta a la que la Ley señala por lo que no es posible desconocer dicho pacto.

Por otro lado, la hipoteca si bien es un derecho real de garantía y es accesoria a una deuda principal de índole civil o comercial es resultado (en el presente caso) de un contrato (por ende de un negocio jurídico) y, por lo tanto, los sujetos que intervienen en el mismo ejercen su autonomía privada en la creación de normas jurídicas privadas, ante ello no es posible que dichas reglas se sometan a las del pagaré que rigen la deuda mercantil y serán usadas (eventualmente) en el proceso de ejecución de dar suma de dinero. La casación no refiere a estos aspectos y sólo alude a la existencia del pacto y afirma que «el pagaré es sólo una prueba (de la existencia de la deuda)». Como suele suceder (casi de modo frecuente) la resolución casatoria que debe ser interpretativa y aportar nociones (y explicaciones) claras y minuciosas en cumplimiento de su función de «enseñanza de cómo usar los preceptos jurídicos» es ambigua, imprecisa e incompleta. 